\title{
Luz e cena: impactos e trocas
}

Light and scene: impacts and exchanges

\section{Roberto Gill Camargo}

Roberto Gill Camargo

Doutor em Comunicação e Semiótica, professor

titular no curso de licenciatura em Teatro e

Dança da Universidade de Sorocaba. Diretor de

teatro e iluminador.

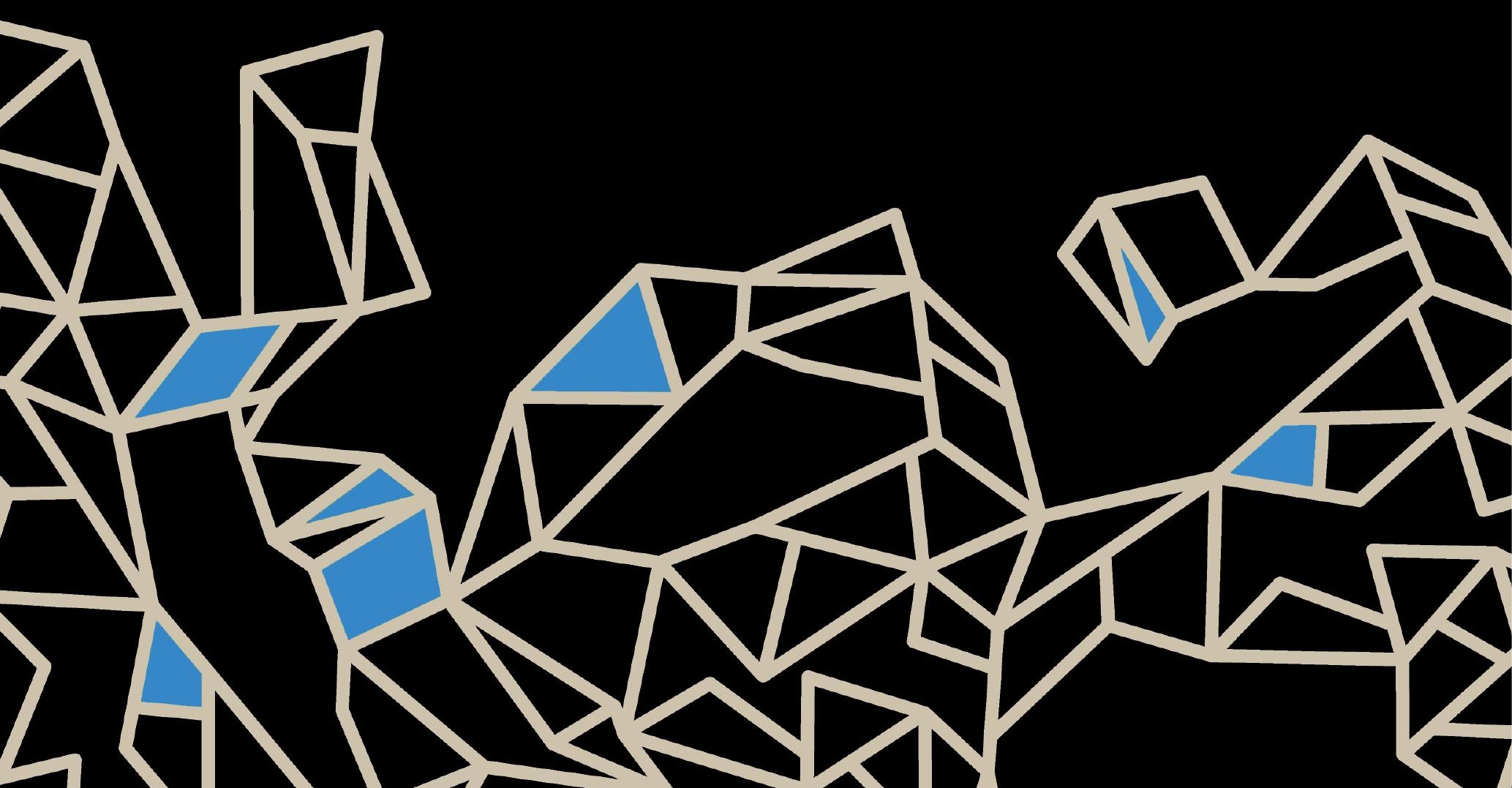




\section{Resumo}

Este artigo analisa alguns aspectos da relação coevolutiva entre a luz e a cena no teatro, a partir dos impactos de uma sobre a outra e consequentes trocas e processos adaptativos. O texto toma por base estudos de Katz e Greiner sobre corpo e ambiente, e busca referências históricas sobre luz nas concepções de Brecht, Artaud e Grotowski.

Palavras-chave: Teatro, Luz, Cena, Coevolução.

\section{Abstract}

This article analyzes some aspects of the coevolutionary relationship between light and scene in theater considering the impacts of one over the other and its resultant exchanges and adaptive processes. The text is based on Katz and Greiner's studies about body and environment, as well as historical references to light in the theater of Brecht, Artaud and Grotowski.

Keywords: Theatre, Light, Scene, Coevolution.

O teatro surgiu das celebrações, procissões e rituais como acontecimentos ao ar livre, fazendo uso da luz natural. Porém, quando passou a ser realizado em locais fechados, foi obrigado a recorrer a meios artificiais, desde o uso da vela, do querosene, do gás, até chegar à eletricidade. Paralelamente à inovação das fontes artificiais de luz, o teatro foi desenvolvendo o aproveitamento da luz para outros fins, além de simplesmente iluminar a cena para torná-la visível.

Chegamos à atualidade com a convicção de que a luz é um recurso poderoso e indispensável ao teatro. Muitas vezes, porém, a luz tem se tornado um espetáculo à parte, completamente divorciado da cena e servindo apenas para criação de efeitos.

Neste estudo, propomos entender a luz como uma fonte de energia que afeta a cena teatral e é afetada por ela. Como consequência, ambas estabelecem trocas incessantes entre si, independentemente do predomínio de uma sobre a outra. 
O deslumbramento diante da luz elétrica com seus poderes não se esgotou lá nos primórdios da conversão dos teatros à eletricidade, mas ainda persiste, em decorrência das inovações técnicas e quantidade de recursos que representam uma tentação aos iluminadores. Se por um lado isso é positivo, pois o desenvolvimento tecnológico traz mais eficiência, economia de consumo e baixa emissão de carbono, por outro pode ser explorado, conforme o uso, para perpetuar o entendimento de que a luz no teatro é para embelezar e criar efeitos.

No final do século XIX, os efeitos de luz produzidos pelos tecidos esvoaçantes da bailarina Loïe Fuller (1862-1928) na Serpentine dance (1891) já anunciavam as possibilidades de se tirar proveito da luz em cena. Em suas performances, Fuller incluía desde recursos muito recorrentes nos espetáculos da época, como a lanterna mágica, cujos slides muitas vezes ela própria se encarregava de pintar, até contribuições que surgiam ao acaso, como a ideia de levar para o palco o efeito de uma fonte luminosa para explorar em cena os seus efeitos de luz colorida sobre a água corrente.

No entanto, para Loïe Fuller, a luz não era apenas um meio capaz de revelar e ocultar os movimentos de seu corpo, mas também um dinâmico parceiro de cena. Ao buscar essa relação dialógica, luz e cor tornavam-se fontes de uma ativa troca com seus movimentos. Mais que uma fonte estática para emoldurar suas várias poses, a luz engajada em sua dança permitia uma variedade de respostas expressivas, conforme mudanças de cor e intensidade (ALBRIGHT, 2007).

A referência às criações de Loïe Fuller retoma as discussões a respeito da interação entre cena e luz, um processo que tende a se modificar na razão da quantidade de transformações cênicas e das respectivas respostas da luz, produzindo uma sucessão de estados visuais.

As negociações entre as informações provenientes da luz e as da cena constituem um fluxo contínuo em que não existe passado nem futuro, apenas o momento presente, em que se dão os impactos e os acordos entre as duas partes envolvidas. A luz causa um impacto ao trazer informações que mudam a aparência visual da cena, assim como a mobilidade dos componentes visuais altera a percepção da luz. É um diálogo contínuo entre os meios "tangíveis" e a "intangibilidade" da luz, conforme expressou o cenógrafo tcheco 
Joseph Svoboda (1920-2002) ao falar sobre o impacto da luz sobre formas, volumes, móveis, acessórios e outros materiais (BABLET, 1970).

A comunicação no teatro é um processo vivo, caracteriza-se pela transitividade e envolve sistemas complexos adaptativos que dialogam entre si. No palco, a energia transforma-se continuamente, produzindo um resultado dinâmico, por meio de trocas e respostas adaptativas. Essa experiência realiza-se na duração de um tempo no qual os acordos físicos, os incidentes, os acasos e os riscos subjazem ao que Patrice Pavis (1982) chama de "ilusão referencial" (p. 15-16). Trata-se de um tempo presente envolvendo atores e espectadores, sem o qual o teatro deixa de ser o que é: uma arte viva.

A ilusão ou a anti-ilusão que o teatro propõe inscrevem-se sobre dados concretos: figurinos que são de algodão, cenários que foram feitos de madeira, atores que são de carne e osso, músicas que se propagam enquanto ondas sonoras e luzes que transmitem radiações eletromagnéticas.

Em cena, os componentes de ordem material subjazem inalienavelmente às intenções comunicativas e dramáticas: a bela perna é da atriz, e não da personagem que ela representa; os figurinos são tecidos de algodão, e a luz não provém senão daqueles refletores pendurados no alto, à vista de todos.

O que muitos livros sobre iluminação cênica costumam dizer, em acordo com os físicos, é que a relação entre luz e cena implica a interação física entre luz e matéria. Há diferenças entre prever o efeito da luz sobre a cena e o resultado concreto que se vê no palco, quando radiações eletromagnéticas passam a interagir com o eletromagnetismo dos corpos. A experiência não se resume apenas no envio da luz, mas na resposta dos corpos em termos de reflexão, absorção e refração.

A codependência que há entre luz e cena não chega a ser tratada diretamente nos livros especializados na área, embora alguns autores a mencionem, usando outras palavras. Em The lighting art, por exemplo, Richard Palmer discute padrões visuais preexistentes na cena e as modificações produzidas por meio dos padrões de luz determinados pelo design. Ao falar sobre percepção e composição, Palmer menciona indiretamente a questão interativa entre luz e matéria, quando se refere à percepção da forma no espaço e quando discute aspectos relacionados à textura, às bordas e aos contrastes nas superfícies. Seu livro convida o leitor a uma série de experiências com 
recortes de figuras geométricas que sofrem alterações conforme se expõem à luz (CAMARGO, 2012).

Os corpos possuem uma energia contida que desprende ou libera elétrons, os quais vibram em resposta às radiações. A luz é uma radiação eletromagnética emitida pela substância (PEDROSA, 2009), o que permite supor, no teatro, a estreita relação que existe entre ela e a cena como instâncias que interagem entre si, não por turnos isolados, mas concomitantemente. Isso explica por que os resultados da luz não dependem unicamente das intenções do iluminador e da encenação, mas das interações que a luz estabelece com os corpos que ilumina no momento em que a cena se realiza. Essa vinculação luz-matéria jamais deixa de existir, sejam quais forem as intenções de ordem ficcional e discursiva atribuídas à luz. $\mathrm{O}$ aspecto visual da cena inclui formas geométricas, não geométricas e abstratas; linhas retas, curvas, onduladas, quebradas, elípticas e circulares, que se constroem e se desconstroem conforme as posturas, os gestos e os movimentos dos atores. A luz responde a cada mudança dessas formas e linhas no espaço.

Imobilizado sob um foco de luz, o ator revela um estado aparentemente constante de reflexos, brilhos e sombras, como se fosse uma escultura iluminada. No entanto, um pequeno gesto que ele fizer, ou uma simples mudança na sua postura, seria o suficiente para que alguns pontos do corpo, que antes estariam mais escuros, tornassem-se agora visivelmente mais claros, enquanto outros permaneceriam obscuros. Sombras no pescoço ou nos olhos, que antes não se viam, passariam a ser notórias; a posição dos braços, conforme apontando para cima, para baixo, para os lados, para trás ou para frente, mudaria significativamente a configuração anterior e produziria novos contrastes de luz e sombra. Quando os pés mudam de posição, e o tronco se curva, instauram-se novas oposições, e eventualmente surgem sombras que o corpo projeta sobre si mesmo.

As experiências com iluminação têm demonstrado que a luz só se realiza completamente quando posta em contato direto com a cena, em seu fluxo intenso e vivo, e não de modo separado, por escolhas e decisões a priori. A vasta margem de imprevisibilidade que permeia a incursão do corpo no espaço-tempo e as relações que há entre os movimentos e a luz fazem que o 
iluminador frequentemente se surpreenda com efeitos não esperados, resultantes de acordos que se instalam no decorrer dos contatos entre luz e cena.

$\mathrm{Na}$ experiência com a luz natural, verificamos constantemente o efeito resultante desse diálogo ininterrupto entre a luz e as coisas. As transformações que a incidência de luz solar acarreta são observáveis nos diversos efeitos produzidos sobre montanhas, plantações, rios, florestas e cenários urbanos. A luz natural se reflete em tudo, revelando aspectos de forma, contraste, volume, textura e cor. Claridade solar e paisagem não se separam, desde o amanhecer até o final da tarde.

Os meios artificiais de iluminação obviamente são limitadíssimos em comparação com a fonte natural. Nas casas, as lâmpadas abrangem uma área restrita; a iluminação pública depende de uma quantidade de postes; os refletores cênicos têm muitos recursos, mas não se pode dizer que não haja restrições, dependendo das dimensões do palco, da posição das varas de iluminação, dos ângulos de incidência etc. As restrições, porém, não excluem a interdependência que há entre a luz e a cena, seja qual for a área de abrangência e os arranjos possíveis nos mais diversos tipos de palco.

O que se observa na relação entre luz e cena é um diálogo silencioso, ainda que tenso e contínuo entre duas forças, uma reagindo ao impacto provocado pela outra. A cena se reconfigura a cada instante, e as condições de luz dão a réplica, num jogo de forças que se complementam.

O aspecto coevolutivo entre cena e luz, para usarmos um termo derivado da biologia, remete às relações entre corpo e ambiente: "As informações do meio se instalam no corpo; o corpo, alterado por elas, continua a se relacionar com o meio, mas agora de outra maneira, o que o leva a propor novas formas de troca. Meio e corpo se ajustam permanentemente num fluxo inestancável de transformações e mudanças" (KATZ; GREINER, 2001, p. 8).

As relações entre luz e cena dependem das mudanças que vão se processando por intermédio do ator ao configurar, desconfigurar e reconfigurar os signos visuais, à medida que ele se movimenta no palco e põe em movimento, diante da luz, figurinos, objetos, adereços, cenários, além de signos diretamente ligados a ele, como a expressão do corpo, dos olhos, dos gestos que acompanham, negam, reforçam ou substituem as suas falas. 
Quando o ator manipula um objeto metálico ou despeja água numa bacia, por exemplo, esses materiais entram em movimento, e sua aparência sofre variações diante da luz. São mudanças muito sutis, quase imperceptíveis, que ocorrem independentemente de serem ou não acentuadas pela iluminação.

As radiações da luz penetram no palco, revelam o espaço, o tempo, as coisas, as expressões, as falas e as palavras. Os olhos do espectador talvez não percebam os impactos e as trocas entre luz e cena, mas certamente isso influencia as suas impressões e modifica seus estados.

O espaço a ser iluminado não é apenas o chamado "espaço dramático" onde ocorre a ação da narrativa, mas todas as construções de espacialidade que se tornam possíveis dentro dele e que vão sendo atualizadas no decorrer da cena, conforme o ator se movimenta nas três dimensões ou se desloca nas dimensões do pensamento, da memória e dos sentimentos, por meio de expressões e palavras.

O movimento livre do ator, nas três dimensões, cria novas construções de espacialidade às quais correspondem situações inéditas de luz. Um reflexo produzido pelo corpo quando está numa posição $X$ pode não se repetir quando o ator se deslocar para a posição $Y$, e parecer completamente diferente dos reflexos na posição $Z$. A reflexão e a absorção não constituem situações fixas, mas estados de claro-escuro que se transformam sem parar, acompanhando os diferentes movimentos do corpo.

O tempo também não é só o "tempo dramático" em que ocorre a ação por exemplo, entre a chegada e a partida de alguém -, mas o tempo que descreve esse intervalo entre chegada e partida. Não são momentos que saltam de um ponto ao outro, mas uma duração, um fluxo temporal que já não pertence apenas ao plano da narrativa, mas ao tempo da realidade compartilhada com os espectadores. A luz irá testemunhar, com seu fluxo, a inconstância e a impermanência do tempo.

É impossível prever a quantidade e a diversidade de informações que o espectador capta das relações entre luz e cena, e muito menos as reações psicológicas que essas relações the podem causar. Da luz, notam-se, em geral, as oposições, mudanças de cor, de foco e de intensidade, ou seja, as marcações explícitas e pré-estabelecidas. Porém, em dimensões menores, 
ocorrem mudanças significativas de estado, as pulsações - o que realmente confere vitalidade à cena. A essas pulsações, talvez o diretor e iluminador americano Robert Edmond Jones (1887-1954) estivesse se referindo em seu livro The dramatic imagination (2004), ao dizer que a iluminação não consiste apenas em lançar luz sobre os objetos, mas sobre o drama: a luz como parte da experiência dramática.

O entendimento da iluminação como recurso externo e dotado de amplos poderes de manipulação sobre a cena tem difundido a ideia de que a luz constitui um meio capaz de aproximar, distanciar, ilustrar, recortar, intensificar, entre outras tantas coisas que se pode fazer com ela. No entanto, essa é a luz que a iluminação cênica produz, e não a iluminação da luz propriamente dita, ou seja, da luz que está intrinsecamente ligada à cena, com cuja vitalidade dialoga incessantemente, no mesmo fluxo de espaço-tempo.

Embora a iluminação cênica costume fazer uso da luz com uma intenção comunicativa explícita, como se exercesse sempre um papel midiático no espetáculo, capaz de produzir e veicular sentidos, a função primária da luz reside na interação física com as coisas que ilumina e o que resulta disso, capaz de transcender os olhos e alcançar o inconsciente.

Estaríamos falando, pois, de uma luz que não permitiria somente ver e entender o significado proposto por intermédio dela, mas capaz de provocar a percepção, de despertar sentimentos, de fruir mais profundamente a experiência cênica. De uma luz atuando em concomitância com a cena; que não se dá a ver por desenhos ou formas criadas a priori, mas por átimos e impermanências que iluminam o material e o imaterial, o tangível e o intangível.

A questão da luz servindo unicamente como veículo de informação sobreposta à cena já havia encontrado resistência nas concepções de Bertolt Brecht (1898-1956), Jerzy Grotowski (1933-1999) e Antonin Artaud (18961948). Atualmente, há muitas experiências em teatro e dança que também rejeitam esse conceito, optando por uma iluminação menos instrumental, menos contaminada pelo cinema e pelo show business, e mais vinculada à presencialidade e à fisicalidade cênica, sem se importar com o fato de que a luz deva significar alguma coisa à parte, além do que ela já significa por si mesma. 
Na concepção de Brecht, a luz apresenta-se como um dos recursos da teatralidade, e não tem a intenção de iludir a audiência, despertar emoções, sugerir estados, provocar sensações, criar símbolos ou expressar conteúdos e formas. Por isso, as fontes de luz devem permanecer à mostra, "para que o teatro funcione como teatro, longe de qualquer concessão ao ilusionismo cênico" (BORNHEIM, 1992, p. 298). A preferência recai sobre a luz geral branca e, muitas vezes, sobre a própria "luz de trabalho" (luz de serviço), numa negação visível da luz com outra função que não seja a da visualidade. Contudo, não se pode dizer que se trata de uma luz "neutra", já que expressa uma atitude, um posicionamento, um modo particular de lidar com os materiais.

Ao comentar a primeira encenação de Um homem é um homem, de 1926, Brecht dizia que a montagem do diretor Jacob Geis (1890-1972) havia evitado implicações, segredos, ambiguidades e meias-luzes, dando preferência aos fatos, à iluminação brilhante, "luz em cada canto", coincidindo com sua preferência por luzes claras e brilhantes, como nos esportes, ao contrário da semiobscuridade das concepções de Reinhardt (WILLET, 1967).

Brecht propunha claridade intensa para que tudo no palco pudesse ser visto e julgado, como se viam as piruetas acrobáticas do music hall, sem a preocupação com sombras e descrição de traços característicos e feições. Talvez ele tenha sido o primeiro a clamar pela luz enquanto luz e não enquanto "escrita", ao dizer: "Dê-nos alguma luz no palco, eletricista. Como podemos nós, dramaturgos e atores, proclamar nossa concepção do mundo em meia-obscuridade? A penumbra induz o sono. Mas precisamos do espectador desperto, mesmo vigilante. Que tenham seus sonhos bem iluminados" (Ibidem, p. 206).

A busca da visualidade como função da luz estava entre os princípios básicos do teatro épico de Brecht: clarear, para que os olhos pudessem ver, como no ringue de boxe e nas quadras esportivas. Ao deixar as fontes de luz aparentes, apresentando-as como tais, explorava a função metalinguística da luz e, ao mesmo tempo, o seu papel primordial no teatro: permitir a visibilidade. No entanto, a estratégia não parecia visar apenas os olhos do espectador, mas a sua capacidade de ler, de perscrutar, de interpretar criticamente a cena.

Grotowski (2010), que buscava um teatro livre de truques e artifícios, centralizando a atenção no ator e na sua capacidade de criação e represen- 
tação, também rejeitava o que poderíamos entender como função referencial e função expressiva da linguagem da luz, ao dar preferência à geral branca ou mesmo à luz de serviço, dependendo do caso.

O simples fato de os refletores projetarem luz sobre um setor da assistência já era suficiente para incluí-lo na cena, como se ele passasse a fazer parte da performance. A valorização do gesto e da expressão facial dos atores não dependia de um arranjo prévio de luzes, mas de uma prática em que os atores iam descobrindo os melhores efeitos nos ensaios, em contato direto com elas. Para Grotowski (2010), muito mais do que um recurso artificial, interessava a luz do homem, a luminosidade, a ideia de que a luz poderia emanar do próprio ator. Para entender isso, comparava a experiência com alguém que depois de muito tempo abandonasse uma gruta, um porão ou um subterrâneo, e viesse à plena luz do dia.

A valorização da luz como componente físico da cena, por meio do qual não se pretende recriar efeitos imitativos nem expressar estados e sentimentos, mas atuar simbolicamente e afetar a percepção, é sugerida nos escritos de Artaud (1984). No Primeiro Manifesto d'O teatro da crueldade, ele expõe sua concepção de luz como parte do jogo dramático, na medida em que ela desempenha uma ação particular sobre o espírito: "Novos efeitos de vibração luminosa devem ser procurados, novos modos de difundir a iluminação em ondas, ou por camadas, ou como uma fuzilaria de flechas incendiárias" ( $p$. 122). Em seguida, fala sobre a necessidade de se reintroduzir na luz elementos de corpo, densidade e opacidade, com o objetivo de produzir calor, frio, raiva, medo etc. (Ibidem).

Brecht, Artaud e Grotowski trazem ideias que se abrem para pensarmos qual seria a função da luz no teatro, além daquilo que se tem visto na literatura e na prática, sobretudo em relação aos modelos ortodoxos de encenação.

Neste artigo, em breves considerações, buscamos retomar os princípios básicos da luz e suas relações com a cena. Diante de novas tendências da dramaturgia e da cena contemporânea, provavelmente seja hora de repensarmos também a questão da luz. No caso, propusemos investigá-la não como representação de uma outra coisa, mas dela própria, em relação de codependência com a cena, uma participando da outra, constituindo-se ambas numa coisa só. Como se disséssemos que a luz é a cena; que ela não vem para 
a cena, como quem chega de fora, pois ela já está na cena. É invisível, sem forma, sem massa, mas presente, pulsante...

\section{Referências bibliográficas}

ALBRIGHT, A. C. Traces of light: absence and presence in the work of Loïe Fuller. Middletown: Wesleyan University, 2007.

ARTAUD, A. O teatro e seu duplo. São Paulo: Max Limonad, 1984.

BABLET, D. Josef Svoboda. Lausanne: L'âge d'homme, 1970.

BORNHEIN, G. Brecht: a estética do teatro. São Paulo: Graal, 1992.

CAMARGO, R. G. Função estética da luz. São Paulo: Perspectiva, 2012.

GROTOWSKI, J. Para um teatro pobre. Lisboa: Forja, 1975.

. O teatro laboratório de Jerzy Grotowski - 1959-1969: textos e materiais

de Jerzy Grotowski e Ludwik Flaszen. São Paulo: Perspectiva e Sesc, 2010.

JONES, R. E. The dramatic imagination: reflections and speculations on the art of the theatre. Nova York: Routledge, 2004.

KATZ, H.; GREINER, C. Corpo e processo de comunicação. São Paulo: Revista Fronteiras, 2001.

PALMER, R. H. The lighting art. Nova Jersey: Prentice Hall, 1998.

PAVIS, P. Voix et images de la scène: essais de semiologie théâtrale. Lille: Presses

Universitaires de Lille, 1982.

PEDROSA, I. Da cor à cor inexistente. Rio de Janeiro: SENAC, 2009.

WILLET, J. O teatro de Brecht. Rio de Janeiro: Zahar, 1967.

Recebido em 09/11/2015

Aprovado em 13/11/2015

Publicado em 21/12/2015 